Article

\title{
Selective Metal Ion Irradiation Using Bipolar HIPIMS: A New Route to Tailor Film Nanostructure and the Resulting Mechanical Properties
}

\author{
Iván Fernández-Martínez ${ }^{1, * \mathbb{D}}$, José A. Santiago ${ }^{1}$, Álvaro Mendez ${ }^{1,2,3}$, Miguel Panizo-Laiz ${ }^{4,5}$ (D), \\ Pablo Diaz-Rodríguez ${ }^{1}$, Lucía Mendizábal ${ }^{6}$, Javier Díez-Sierra ${ }^{6} \mathbb{D}$, Cristina Zubizarreta ${ }^{6}(\mathbb{D}$, \\ Miguel A. Monclus ${ }^{3}\left(\mathbb{D}\right.$ and Jon Molina-Aldareguia ${ }^{2,3} \mathbb{D}$
}

check for updates

Citation: Fernández-Martínez, I.; Santiago, J.A.; Mendez, Á.; Panizo-Laiz, M.; Diaz-Rodríguez, P.; Mendizábal, L.; Díez-Sierra, J.; Zubizarreta, C.; Monclus, M.A.; Molina-Aldareguia, J. Selective Metal Ion Irradiation Using Bipolar HIPIMS: A New Route to Tailor Film Nanostructure and the Resulting Mechanical Properties. Coatings 2022, 12, 191. https://doi.org/10.3390/ coatings12020191

Academic Editor: Joerg Vetter

Received: 31 December 2021

Accepted: 27 January 2022

Published: 1 February 2022

Publisher's Note: MDPI stays neutral with regard to jurisdictional claims in published maps and institutional affiliations.

Copyright: (C) 2022 by the authors. Licensee MDPI, Basel, Switzerland. This article is an open access article distributed under the terms and conditions of the Creative Commons Attribution (CC BY) license (https:// creativecommons.org/licenses/by/ $4.0 /)$.
1 Nano4Energy SL, José Gutierrez Abascal, 2, 28006 Madrid, Spain; joseantonio.santiago@nano4energy.eu (J.A.S.); alvaro.mendez@nano4energy.eu (Á.M.); pablo.diazr@nano4energy.eu (P.D.-R.)

2 Mechanical Engineering Department, Universidad Politécnica de Madrid, 28006 Madrid, Spain; jon.molina@imdea.org

3 IMDEA Materials Institute, Eric Kandel, 2, Getafe, 28906 Madrid, Spain; miguel.monclus@imdea.org

4 Departamento de Física Aplicada e Ingeniería de Materiales, Universidad Politécnica de Madrid, 28006 Madrid, Spain; Miguel.panizo.laiz@upm.es

5 Centro Láser, Universidad Politécnica de Madrid, Calle Alan Turing 1, 28031 Madrid, Spain

6 Fundación Tekniker. C. Iñaki Goenaga, 5, 20600 Gipuzkoa, Spain; lucia.mendizabal@tekniker.es (L.M.); javier.diez@tekniker.es (J.D.-S.); cristina.zubizarreta@tekniker.es (C.Z.)

* Correspondence: ivan.fernandez@nano4energy.eu

\begin{abstract}
This manuscript introduces and experimentally demonstrates a novel concept of selective metal ion irradiation by combining bipolar HIPIMS with conventional DC magnetron sputtering operation and simple DC biasing. The addition of the positive pulse to a conventional HIPIMS discharge accelerates the predominantly metal ions created during the negative HIPIMS phase with an energy proportional to the positive pulse amplitude and ionization state. Two distinct metal elements with large difference in atomic mass $(\mathrm{Cr}$ and $\mathrm{Nb})$ are used on this work to irradiate a TiAlN matrix which is being deposited by conventional DCMS. The positive acceleration voltages used for both $\mathrm{Cr}$ and $\mathrm{Nb}$ discharges were varied between 0 to $+200 \mathrm{~V}$ to analyze the influence of $\mathrm{Nb}$ and $\mathrm{Cr}$ metal ion irradiation on the mechanical and microstructural properties of TiAlN films. Even though the total metal ion incorporation into the TiAlN matrix for both $\mathrm{Cr}$ and $\mathrm{Nb}$ is less than $10 \%$ at $\%$, strong effects are observed on the resulting film properties. It was observed that use of the lighter metal ion $\mathrm{Cr}$ is more beneficial than the heavier metal ion $\mathrm{Nb}$. The $\mathrm{Cr}$ bombardment allows a hardness improvement from 7 to $22 \mathrm{GPa}$ as well as a reduced film accumulated stress at the highest positive acceleration voltage. From the XRD measurements it is observed that the $\mathrm{Cr}$ atoms are inserted into the TiAlN cubic matrix maintaining its crystalline structure. However, the bombardment with the high-mass metal ion $(\mathrm{Nb})$ promotes the deformation of the cubic TiAlN matrix, resulting in a spinodal decomposition and further degradation of the crystalline structure with the appearance of the hexagonal wurtzite-type Al-rich phase. This is also translated to the resulting film mechanical properties, as hardness rapidly decreases from 25 to $10 \mathrm{GPa}$ and stress increases linearly with the positive voltage acceleration.
\end{abstract}

Keywords: HIPIMS; bipolar; transition metal nitrides

\section{Introduction}

Metal ion irradiation combining HIPIMS discharges and pulsed bias synchronization has been demonstrated in recent years to be a powerful method to achieve an accurate management on film nanostructure and phase control for the deposition of transition metal (TM) nitrides [1]. It allows the deposition of films with optimum mechanical properties as 
well as reduced accumulated stress compared to films deposited with gas-ion bombardment typical for direct current magnetron sputtering (DCMS). The selective attraction of metal ions at the substrate position optimizes the metal ion energy and momentum required during film growth. The target to substrate distance determines the time delay between the magnetron and bias voltage pulses which is primarily investigated by mass spectroscopy. In general, this method has been demonstrated for static configurations, i.e., the target to substrate separation remains constant once the optimum time delay has been selected [2].

In this work, this concept of selective metal ion irradiation is extended by combining bipolar HIPIMS with conventional DC magnetron sputtering operation and DC biasing. The concept of bipolar HIPIMS was introduced some years ago by different groups and consists of applying a positive pulse with controlled pulse width and amplitude voltage after the conventional HIPIMS negative pulse [3,4]. This positive pulse allows the controlled acceleration of the positive ions (both metal and gas, but predominantly metal ions at the end of the HIPIMS pulse [5]) towards the substrate, thus, promoting improved film properties such as reduced stress [6], higher film densification giving rise to improved mechanical properties—such as hardness or wear resistance [7]-, or better coverage of 3D complex parts [8]. Moreover, it has been recently demonstrated that using bipolar HIPIMS with a substrate at ground potential results in a similar ion current profile as in conventional HIPIMS with a synchronized pulsed bias with the same delay and timing as the positive pulse [9].

In the novel hybrid method explained in this work, a first magnetron is equipped with a target material (Me1, in this case a 50:50 at\% composite of Ti and $\mathrm{Al}$ ) operated in conventional DCMS to deposit a first film on the substrate. The magnetic configuration of this first magnetron is balanced, i.e., it does not provide high ion assistance to the depositing film. This first layer is exposed to the subsequent metal ion irradiation generated in the second magnetron operated in bipolar HIPIMS mode (Me2). Depending on the required coating properties, the selected metal ion (Me2) can be a heavy ion such as $\mathrm{Mo}, \mathrm{Nb}$, or $\mathrm{W}$ to promote a large number of atoms recoil in the depositing matrix-and thus, enhanced growing film densification-or a light ion such as Al or Si to generate a gentle bombardment or even, sub-plantation. The main advantage of this approach, as compared to the synchronized pulsed bias solution, is the reduction of the influence of the target-tosubstrate distance in the metal ion acceleration, which allows the use of this technology in different industrial batch-type coaters or in the deposition of large substrates with complex shapes, where a wide range of target-to-substrate distances are typically found. This new coating process has been used for the deposition of hard, dense TM Nitrides commonly used in the metalworking industry, such as the case of wear protective coatings for cutting tools, molds and dies [10]. This work studies the influence of $\mathrm{Nb}$ and $\mathrm{Cr}$ ion irradiation on the mechanical properties of TiAlN films. These ions were selected as they show a large difference in mass.

\section{Experimental Details}

The film growth process consists of three different phases which are intentionally separated in the time domain, as shown in Figure 1. A simple case with two different metals (Me1, Me2) sputtered in the presence of noble and reactive gases (Argon and Nitrogen) is explained. Me1 means the material of the target operated in DCMS while Me2 means the material of the HIPIMS target. Even though the primarily use of this method would be for TM nitrides such as TiAlN, it can be extended to a wide type of coatings able to be performed by magnetron sputtering such as refractory metals, oxides, carbides, or borides.

(i) In Phase 1, a flux of Me1 atoms with low ionization-intrinsic to DCMS discharges-is deposited onto the low voltage biased substrate, typically as low as $-20 \mathrm{~V}$ which is in the range of the substrate floating potential under a DCMS discharge. This reduced Bias voltage value allows the low energy acceleration of the small fraction of ionized Me1 as well as the noble and reactive gases present in the system. This growing phase 
gives rise to the deposition of a thermodynamically stable phase with intrinsic poor mechanical properties. But, on the other hand, it minimizes the amount of noble gas-argon in this case- incorporated into the growing film which typically leads to high accumulated stress.

(ii) In Phase 2, the HIPIMS magnetron discharge is ignited by applying the negative voltage pulse to the second magnetron, giving rise to the generation of a highly ionized Me2 ion discharge. In static configuration as shown in Figure 1, Me1 and Me2 irradiation coexist during this short period of time, being in which Me2 also accelerated towards the substrate with an energy proportional to the bias voltage. However, in a dynamic deposition process, Me1 and Me2 are deposited sequentiallymagnetrons are placed at different chamber position-and the substrate travels inside the chamber between the different plasma positions.

(iii) In Phase 3, a positive pulse is applied to the HIPIMS magnetron. This allows the acceleration of Me2 with high energy towards the growing film, which could lead to the densification of the material deposited between the HIPIMS positive pulses (Me1) or even sub-plantation of Me2 ions into the Me1 matrix for high energy ranges $(>100 \mathrm{eV})$. The Me2 selection might vary from light metal ions such as $\mathrm{Al}$ for the sub-plantation of $\mathrm{Al}+$ ions giving rise to metastable cubic TiAlN coatings with high $\mathrm{Al}$ content (up to $66 \%$ at), to heavy metal ions such as $\mathrm{Mo}, \mathrm{Nb}$, or $\mathrm{W}$ to promote film densification through effective low energy recoil.

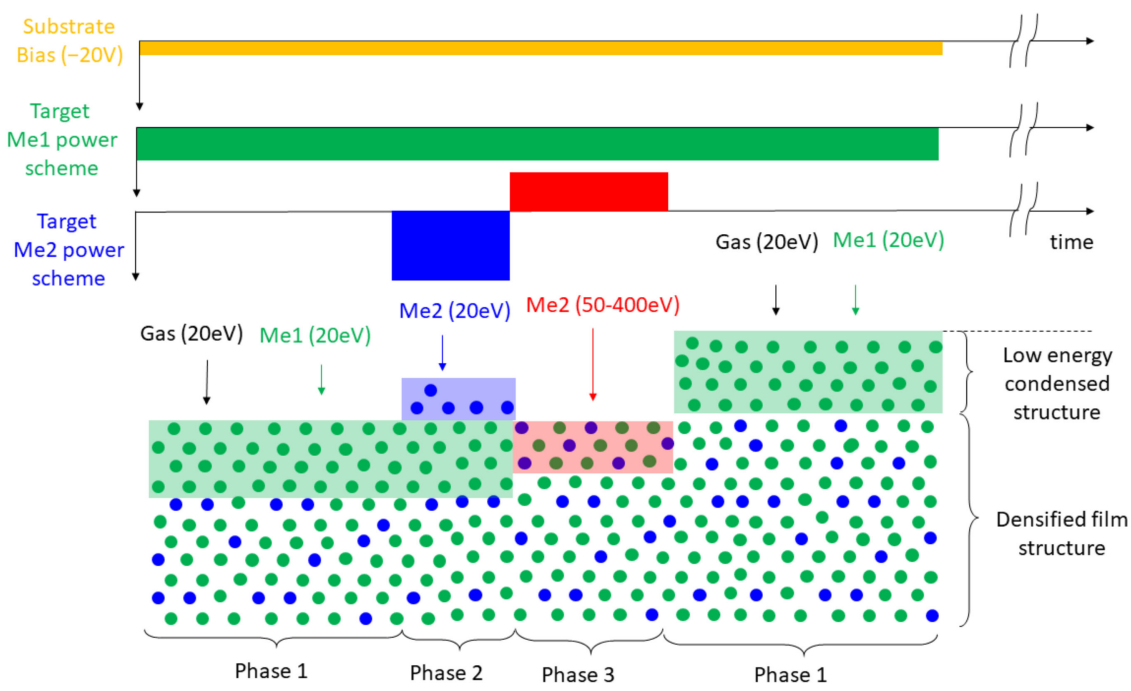

Figure 1. Schematics of the film growth process consisting in three different phases which are intentionally separated in the time domain.

This growth model is valid for systems with static or dynamic deposition, such as in the case of a batch coater where the substrate is also exposed sequentially to the different plasmas present in the chamber. The growing film is sequentially exposed to the combination of low ionized and low energetic deposition performed by DCMS and high energetic metal impingement. It is clear to the authors that despite the ion mass, other parameters such as ionization potential, gas rarefaction, reactivity towards nitrogen will affect or the large transit time between the different species are affecting the relative metal/gas ion ratio at the substrate which may in turn affect the changes to crystal structure. This paper will be an initial paper demonstrating the possibilities of this technology which will be followed by a series of work devoted to have a better understanding of the phenomena happening at the substrate position for different metal species.

An industrial batch coater with rectangular magnetrons is used for the experiments (Figure 2). A TiAl target (pressed powder, 50:50 at\%) is selected for the deposition of the TiAlN reference film material by DCMS. A Gencoa (Liverpool, UK) rectangular magnetron 
(400 mm $\times 100 \mathrm{~mm})$ with a balanced magnetic field configuration which results in a very low bombardment to the depositing film is used for the TiAlN deposition. A second rectangular magnetron $(400 \mathrm{~mm} \times 100 \mathrm{~mm}$ ) with strong unbalanced configuration is employed to generate and accelerate the metal ions (Me2 as described in the above section). Elements with large difference in mass are selected to evaluate the effect of the metal ion impinging on the resulting $\operatorname{TiAl}(1-\mathrm{x}) \mathrm{Me} 2(\mathrm{x}) \mathrm{N}$ film properties: niobium $(\mathrm{Nb})-m_{\mathrm{Nb}}=92.9 \mathrm{amu}$, and chromium $(\mathrm{Cr})-m_{\mathrm{Cr}}=52.0 \mathrm{amu}$. A $10 \mathrm{~kW}$ HipV power supply with positive pulse capacity is employed to feed the HIPIMS cathode, while an AE Pinnacle power supply is used for the DCMS. A HipV bias power supply is employed to apply the low voltage straight DC bias $(-20 \mathrm{~V}$ and $-70 \mathrm{~V})$. The substrate table consist of three spindles of $150 \mathrm{~mm}$ diameter each connected to a $350 \mathrm{~mm}$ rotating table. The substrates are clamped in the different spindles and subject to 2 -fold rotation during deposition.

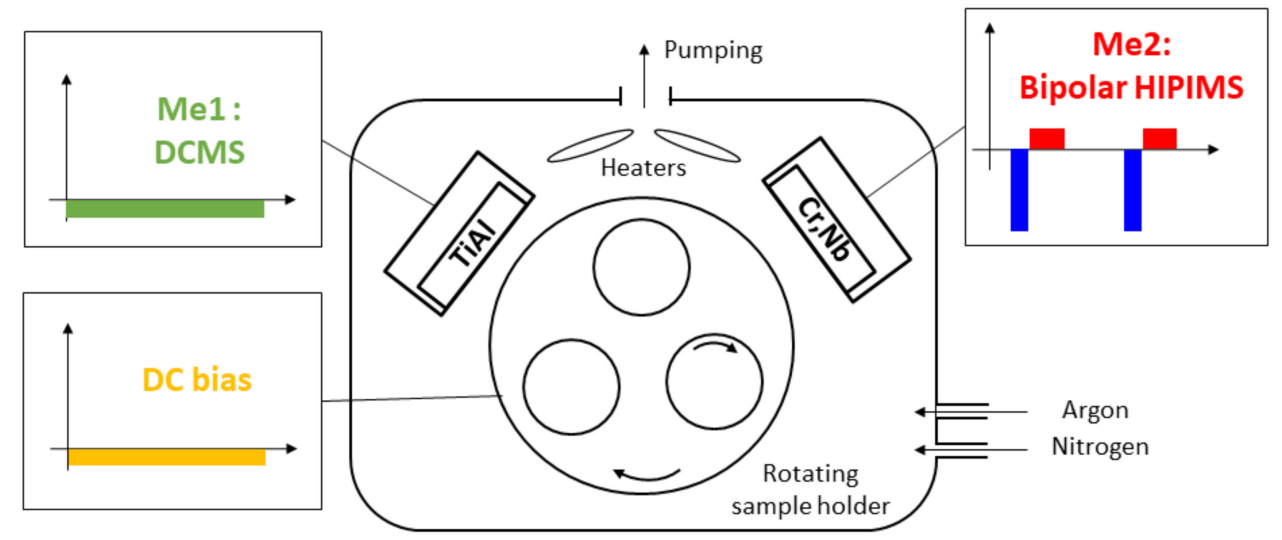

Figure 2. Schematics configuration of the industrial batch coater.

The film characterization was carried out in a set of different substrates: Silicon (001) wafers were used for the thickness, morphology, and composition measurements in SEMEDX; electropolished $304 \mathrm{~L}$ stainless steel $\left(50 \times 50 \mathrm{~mm}^{2}\right)$ for the XRD characterization; M2 HSS coupons ( $10 \mathrm{~mm}$ diameter) for the nanoindentation hardness measurement; thin steel strips ( $0.1 \mathrm{~mm}$ thickness, $40 \mathrm{~mm}$ length and $5 \mathrm{~mm}$ width) for the stress calculation using Stoney's equation.

Two different series of $\operatorname{TiAl}(1-\mathrm{x}) \mathrm{Me} 2(\mathrm{x}) \mathrm{N}(\mathrm{Me} 2 \mathrm{Cr}, \mathrm{Nb})$ were deposited to evaluate the effect of mass and energy of the metal ion impinging the TiAlN matrix deposited. A straight DC bias of $-70 \mathrm{~V}$ was applied during deposition. Also, a third $(\mathrm{TiAl})_{1-\mathrm{x}} \mathrm{Nb}_{\mathrm{x}} \mathrm{N}$ sample was deposited with a straight Bias as low as $-20 \mathrm{~V}$ for comparison with the series at $-70 \mathrm{~V}$ Bias.

After $1 \mathrm{~h}$ heating at $300^{\circ} \mathrm{C}$, a pulsed argon glow discharge $(450 \mathrm{~V}-150 \mathrm{kHz})$ is applied for $30 \mathrm{~min}$ prior to film deposition to remove the substrates contaminants and native oxide, followed by a thin Me2 ( $\mathrm{Nb}$ or $\mathrm{Cr}$ ) bonding layer deposited by HiPIMS for 5 min. The same HIPIMS power supply and pulsing parameters are used for both the bonding layer and the subsequent metal nitride irradiation to ensure process stabilization during nitrogen addition, so as the amplitude of the positive pulse is also varied during bonding layer deposition in the series. The Me2 average power was adjusted to have a similar concentration of $\mathrm{Me} 2$ in the films $\mathrm{x}=\mathrm{Me} 2 /(\mathrm{Al}+\mathrm{Ti}+\mathrm{Me} 2)$-in the range of $0.1-$ and compare the effect of ion mass in the mechanical properties of the resulting film. This assumption results in an average power of $1.5 \mathrm{~kW}$ for $\mathrm{Nb}$, and $1.0 \mathrm{~kW}$ in the case of $\mathrm{Cr}$. The pulsing parameters were the same in both cases: negative pulse width: 35 us, positive pulse width: $100 \mu \mathrm{s}$; repetition frequency: $1 \mathrm{kHz}$ ); delay between negative and positive pulse: $3 \mu \mathrm{s}$; the amplitude of the positive pulse $\left(V_{\text {pos }}\right)$ was varied between $0 \mathrm{~V}$ and $+200 \mathrm{~V}$; repetition frequency: $1 \mathrm{kHz}$ ). The following operating voltage and peak current were obtained during deposition: $540 \mathrm{~V}-110 \mathrm{~A}\left(0.28 \mathrm{~A} / \mathrm{cm}^{2}\right)$ for $\mathrm{Cr}$, and $630 \mathrm{~V}-160 \mathrm{~A}\left(0.40 \mathrm{~A} / \mathrm{cm}^{2}\right)$ for $\mathrm{Nb}$. 
In all cases, the TiAlN matrix was deposited on DCMS with a constant average power of $3 \mathrm{~kW}(350 \mathrm{~V}-8.5 \mathrm{~A})$ as well as gas flows $(\mathrm{Ar}=56 \mathrm{sccm}, \mathrm{N} 2=24 \mathrm{sccm})$, giving rise to a total pressure of $\mathrm{P}\left(\mathrm{Ar}+\mathrm{N}_{2}\right)=7 \times 10^{-3}$ mbar. The rotation speed is maintained at $5 \mathrm{rpm}$.

The selection of pulsing parameters (in both the positive and negative phases) was based on the experiments published in [11], where it is demonstrated that the application of a short negative pulse followed by a larger positive pulse maximizes the fraction of positive ions accelerated during the positive phase. As the negative pulse time is longer than the time-of-flight of the metal ions, these ions reach the substrate without being accelerated. Obviously, this parameter selection depends on the target-to-substrate distance, which ranges between 8 to $15 \mathrm{~cm}$ in the current system configuration.

The TiAlN deposition rate is calculated to be approximately $2.5 \mu \mathrm{m} / \mathrm{h}$. Based on the previous results in the same batch coater, it is assumed that most of the film material would be deposited when the substrate faces the operating magnetron (in this case, the TiAl DCMS), thus, a TiAlN nano-layer of a maximum thickness of $3.3 \mathrm{~nm}$ would be deposited on each pass (approximately $8 \mathrm{ML}$ ) [12]. Still, it is well known for batch coaters that a certain degree of depositing material reaches the substrate in off-angle positions or at positions very distant from the ignited magnetron, so further investigations to identify the accurate nano-layer thickness should be carried out by, for example, transmission electron microscopy. In the case of the metal ions (Me2), a low thickness $<1$ monolayer is expected as corroborated from the composition measurements showing an element atomic composition $\operatorname{TiAl}(1-x) \operatorname{Me} 2(x) \mathrm{N}, \mathrm{x}<10 \%$ at $\%$.

Samples are labelled as $(\mathrm{Cr}, \mathrm{Nb}) \times \mathrm{VByV}$ in the graphs, being $\mathrm{x}$ the positive voltage amplitude $(x=0 \mathrm{~V},+50 \mathrm{~V},+100 \mathrm{~V}$ and $+200 \mathrm{~V}$ for $\mathrm{Nb}$ and $\mathrm{x}=0 \mathrm{~V},+50 \mathrm{~V}$ and $+200 \mathrm{~V}$ for $\mathrm{Cr})$ and $y$ the bias voltage used for deposition $(x=-20 \mathrm{~V}$ and $-70 \mathrm{~V})$.

\section{Results and Discussion}

\subsection{Bipolar HIPIMS Plasma Characterization}

Selected HIPIMS target voltage and current waveforms for $\mathrm{V}_{\text {pos }}=0,+35,+50,+75$, $+100,+125,+150$ and $+200 \mathrm{~V}$ are shown in Figure 3 -left. The DC bias voltage and current waveforms for the different $V_{\text {pos }}$ values are also shown in Figure 3-right. It is worth mentioning the presence of an increase of the magnetron reverse current during the positive pulse proportional with the amplitude of the positive voltage which is also reflected in the ion flux acceleration towards the substrate. The average ion flux $\left(\mathrm{j}_{\mathrm{s}}\right)$-calculated from the bias current and substrate table area-during the positive phase increases from $0.07 \mathrm{~mA} / \mathrm{cm}^{2}$ at $V_{\text {pos }}=0 \mathrm{~V}$ to $0.2 \mathrm{~mA} / \mathrm{cm}^{2}$ at $V_{\text {pos }}=200 \mathrm{~V}$, which is comparable to the ion flux during the negative pulse: $0.18 \mathrm{~mA} / \mathrm{cm}^{2}$. As it has been considered interesting to discuss the DC bias voltage behaviour as a function of time the waveform with $-20 \mathrm{~V}$ DC bias applied is also shown. Even though a $-20 \mathrm{~V}$ bias voltage value is applied to the substrate, the measured value differs during both the negative pulse and the switching from positive to negative in the HIPIMS magnetron. The increase of substrate voltage from $-20 \mathrm{~V}$ to $-30 \mathrm{~V}$ during the HIPIMS negative pulse is due to the plasma potential increase, inherent to a conventional HIPIMS discharge. If the floating substrate potential were observed under these magnetron conditions, a floated substrate potential value of around $-30 \mathrm{~V}$ would be measured. On the other hand, it is difficult to explain the collapse of the bias voltage during the magnetron voltage switch from negative to positive, but it is probably attributable to the large positive voltage overshoot. The reaction time of the bias power supply is not short enough to adjust the voltage during this fast transient. 

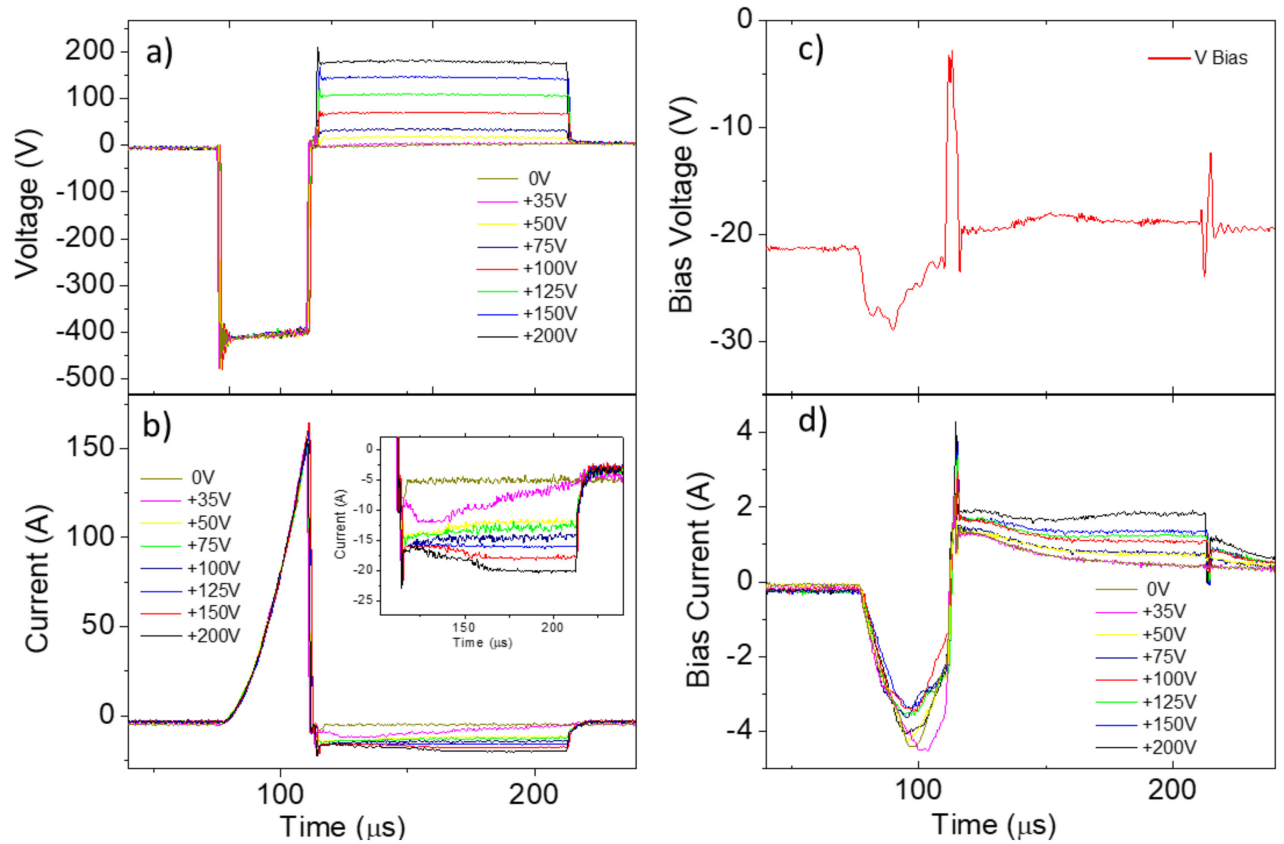

Figure 3. Left: Voltage (a) and current (b) waveforms for the magnetron during $\mathrm{Nb}$ operation. Right: Voltage (c) and current (d) waveforms for the Bias during $\mathrm{Nb}$ operation.

\section{Coating Properties}

The atomic composition of the $(\mathrm{TiAl})_{1-\mathrm{x}}(\mathrm{Cr}, \mathrm{Nb})_{\mathrm{x}} \mathrm{N}$ films deposited onto silicon is shown in Table 1. The power levels of the DCMS TiAlN magnetron $(3 \mathrm{~kW})$ and the bipolar HiPIMS cathodes ( $1 \mathrm{~kW}$ for $\mathrm{Cr}, 1.5 \mathrm{~kW}$ for $\mathrm{Cr}$ ) was adjusted to obtain a the composition fraction of $\mathrm{Cr}$ and $\mathrm{Nb}$ into the $(\mathrm{TiAl})_{1-\mathrm{x}}(\mathrm{Cr}, \mathrm{Nb})_{\mathrm{x}} \mathrm{N}$ film is around 10 at $\%$. The argon to nitrogen ratio was selected to provide a stoichiometric transition metal nitride film (N2/Ar flow ratio of 0.42). On the other hand, there are no changes in deposited film deposition as a function of the positive pulse. This means that the energetic metal ions incorporate into the TiAlN matrix without creating a distortion in the $\mathrm{Al}$ to Ti ratio, which remains constant for the different Me2 ion energies. The relatively high oxygen content of the reference TiAlN might be related with the high film porosity of the TiAlN matrix (deposited with low ion bombardment) and the subsequent oxidation after exposure to air. This assumption is corroborated with the columnar structure found with the SEM cross sections as well as the poor mechanical properties measured by nanoindentation (see Figures $4 \mathrm{a}$ and $5 \mathrm{a}$ ). The oxygen signal disappears as soon as the energetic $\mathrm{Cr}$ o $\mathrm{Nb}$ metals are incorporated.

Table 1. Atomic composition of the $(\mathrm{TiAl})_{1-\mathrm{x}}(\mathrm{Cr}, \mathrm{Nb})_{\mathrm{x}} \mathrm{N}$ series.

\begin{tabular}{|c|c|c|c|c|c|c|c|c|c|c|}
\hline \multirow{2}{*}{$\begin{array}{l}\text { Metal } \\
\text { Ion }\end{array}$} & \multirow{2}{*}{$\begin{array}{l}\text { Sample } \\
\text { code }\end{array}$} & \multirow{2}{*}{$\begin{array}{l}\text { Positive } \\
\text { Pulse (V) }\end{array}$} & \multicolumn{5}{|c|}{ Composition (at\%) } & \multicolumn{3}{|c|}{$x$} \\
\hline & & & $\mathrm{Ti}$ & Al & $\mathrm{Me}(\mathrm{Cr}, \mathrm{Nb})$ & $\mathbf{N}$ & $\mathbf{O}$ & $\mathrm{Me} /(\mathrm{Me}+\mathrm{Al}+\mathrm{Ti})$ & $(\mathrm{Me}+\mathrm{Al}+\mathrm{Ti}) / \mathrm{N}$ & $\mathrm{Al} /(\mathrm{Al}+\mathrm{Ti})$ \\
\hline \multirow{3}{*}{$\mathrm{Me}=\mathrm{Cr}$} & Cr_0 & 0 & 16.74 & 18.37 & 9.61 & 55.3 & - & 0.21 & 0.81 & 0.52 \\
\hline & Cr_100 & 100 & 15.55 & 17.72 & 10.67 & 56.1 & - & 0.24 & 0.78 & 0.53 \\
\hline & Cr_200 & 200 & 17.41 & 18.25 & 9.48 & 54.9 & - & 0.21 & 0.82 & 0.51 \\
\hline \multirow{4}{*}{$\begin{array}{c}\mathrm{Me}= \\
\mathrm{Nb}\end{array}$} & Nb_0 & 0 & 17.36 & 18.96 & 7.16 & 56.5 & - & 0.16 & 0.77 & 0.52 \\
\hline & Nb_50 & 50 & 16.79 & 17.73 & 9.21 & 56.3 & - & 0.21 & 0.78 & 0.51 \\
\hline & Nb_100 & 100 & 15.7 & 17.55 & 8.1 & 58.7 & - & 0.2 & 0.71 & 0.53 \\
\hline & $\mathrm{Nb} \_200$ & 200 & 18.06 & 18.93 & 7.17 & 55.8 & - & 0.16 & 0.79 & 0.51 \\
\hline- & Ref & Ref TiAlN & 20.03 & 23.2 & - & 46.6 & 9 & - & 0.93 & 0.53 \\
\hline
\end{tabular}




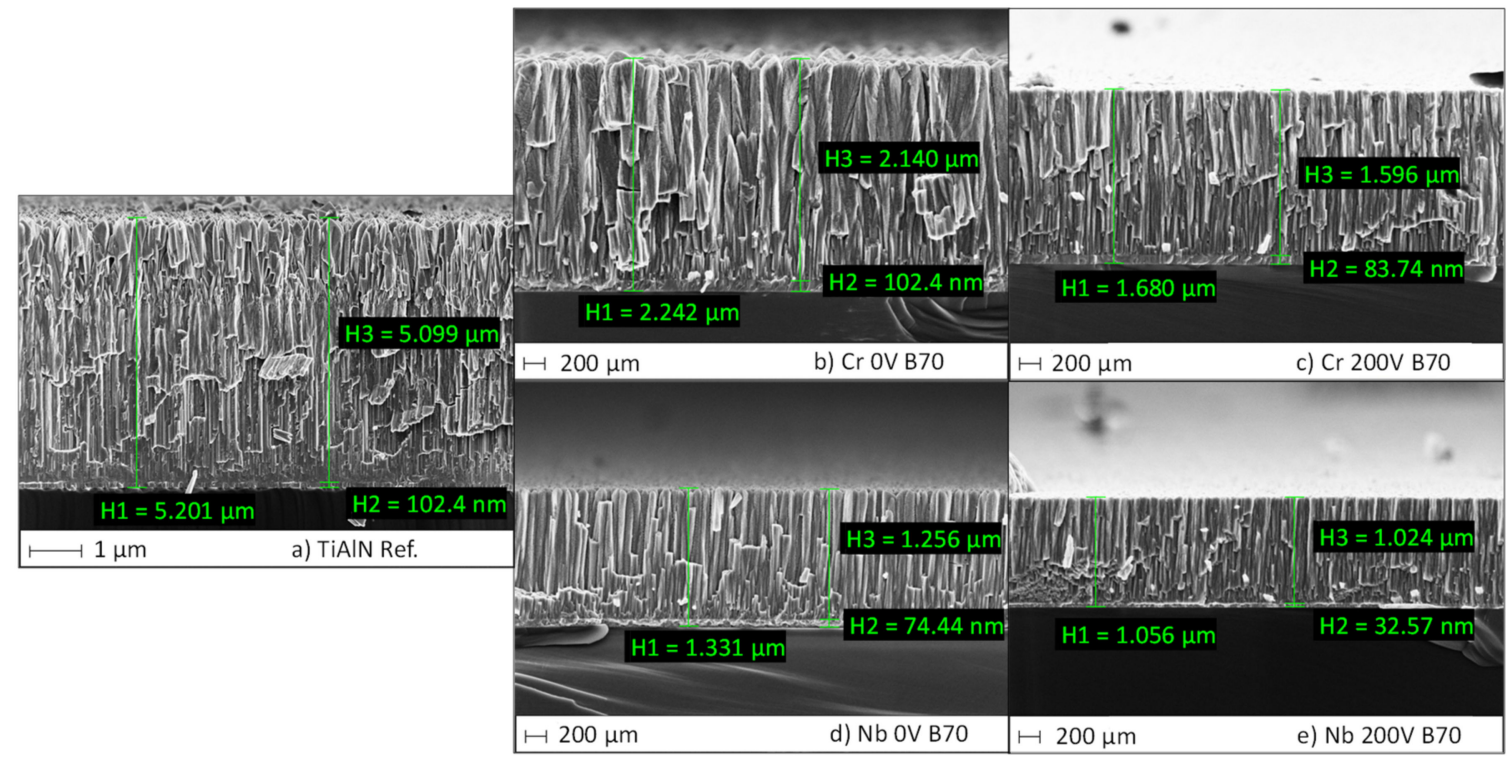

Figure 4. SEM cross sections of the reference TiAlN sample (left, (a)) prepared with a straight DC bias of $-70 \mathrm{~V}$, and $(\mathrm{TiAl})_{1-x}(\mathrm{Cr}, \mathrm{Nb})_{x} \mathrm{~N}$ films deposited with no positive accelerating voltage (middle, $(\mathbf{b}, \mathbf{d}))$ and $+200 \mathrm{~V}$ accelerating voltage (right, $(\mathbf{c}, \mathbf{e}))$.

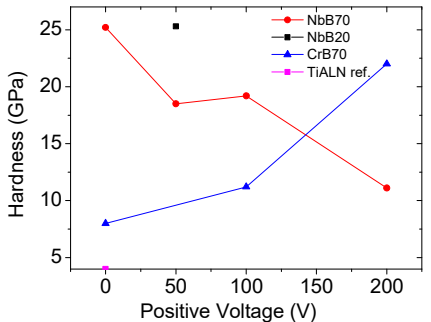

(a)

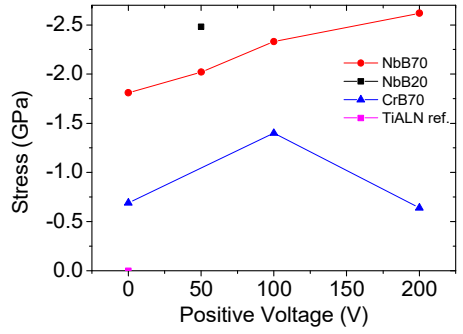

(b)

Figure 5. Nanoindentation hardness (a) and accumulated stress (b) as a function of the $\mathrm{Nb}, \mathrm{Cr}$ positive accelerating voltage.

The fracture cross sections SEM images for the reference TiAlN, sample as well as the selected $(\mathrm{TiAl})_{1-x}(\mathrm{Cr}, \mathrm{Nb})_{\times} \mathrm{N}$ samples with no positive and $V_{\text {pos }}=+200 \mathrm{~V}$ accelerating voltage are shown in Figure 4 . Even though the films remain with a clear columnar morphology for the increasing positive pulse amplitudes, a reduction in the film roughness is observed for the samples exposed to the selective metal ion irradiation. This is also accompanied with a reduction of the deposition rate, as the reference deposition rate for the TiAlN DCMS sample is $2.5 \mu \mathrm{m} / \mathrm{h}$, dropping to $0.8 \mu \mathrm{m} / \mathrm{h}$ and $0.5 \mu \mathrm{m} / \mathrm{h}$ for both $\mathrm{Cr}$ and $\mathrm{Nb}$ accelerated with a positive voltage of $+200 \mathrm{~V}$. The decrease in deposition rate is attributed to a combination of re-sputtering and densification of the growing film upon metal ion irradiation.

The resulting mechanical properties of the $(\mathrm{TiAl})_{\mathrm{x}}(\mathrm{Cr}, \mathrm{Nb})_{1-\mathrm{x}} \mathrm{N}$ films are presented in Figure 4. The nanoindentation hardness as well as the accumulated stress is plotted as a function of the positive accelerating voltage for a sample preparation DC bias voltage of $-70 \mathrm{~V}$. Also, a $(\mathrm{TiAl})_{1-\mathrm{x}}(\mathrm{Nb})_{\mathrm{x}} \mathrm{N}$ film deposited with a bias voltage of $-20 \mathrm{~V}$ is included for comparison purposes.

Two different behaviors are observed depending on the ion chosen for irradiating the samples, namely $\mathrm{Nb}$ or $\mathrm{Cr}$. In the case of $\mathrm{Cr}$, the hardness increases from $7 \mathrm{GPa}$ to $22 \mathrm{GPa}$ as the positive pulses goes from 0 to $+200 \mathrm{~V}$. This trend is expected due to the higher densification (low-energy recoil creation) as the energy of the $\mathrm{Cr}$ ions increases. It is also 
worth mentioning that this film densification is not accompanied by an increase in the film stress (see Figure 5b), which is a good signature of the metal ion irradiation as compared to the conventional Ar ion assistance on DCMS processes resulting in Ar gas entrapment and high compressive stress.

On the other hand, the $\mathrm{Nb}$ irradiated films show an opposite behavior: even though the films present a denser structure as observed on the SEM pictures (see Figure 3d,e) a linear reduction of hardness accompanied with a linear increase of the film stress is observed. Moreover, the sample deposited with no $\mathrm{Nb}$ acceleration voltage already shows a high hardness value of $25 \mathrm{GPa}$ as compared to the same sample deposited with $\mathrm{Cr}$. This would imply that the initial selection of parameters for the heavy mass ion $(\mathrm{Nb})$ were too energetic to maintain the good mechanical properties. Thus, for comparison, a $(\mathrm{TiAl})_{1-\mathrm{x}}(\mathrm{Nb})_{\mathrm{x}} \mathrm{N}$ film was deposited with a lower Bias voltage of $-20 \mathrm{~V}$ and $+50 \mathrm{~V}$ acceleration voltage. In this case, a higher hardness value of $25 \mathrm{GPa}$ is observed together with a high compressive stress value of $-2.5 \mathrm{GPa}$.

It is well known that Ti50Al50N forms a metastable cubic phase, posing an important challenge regarding phase stability. Under strong ion irradiation conditions, the precipitation of the cubic TiAlN phase into wurtzite AlN phase can be observed, thus hindering the film mechanical properties.

The XRD patterns of the $(\mathrm{TiAl})_{1-\mathrm{x}}(\mathrm{Cr})_{\mathrm{X}} \mathrm{N}$ and $(\mathrm{TiAl})_{1-\mathrm{x}}(\mathrm{Nb})_{\mathrm{X}} \mathrm{N}$ films as a function of the applied positive pulse are shown in Figure $6 a, b$, respectively. The XRD pattern of a TiAlN DCMS film deposited under similar conditions is also shown for reference. The peaks at $2 \theta \approx 43.5^{\circ}$ corresponds to the $\gamma$-Fe lattice coming from the steel substrate in all cases.

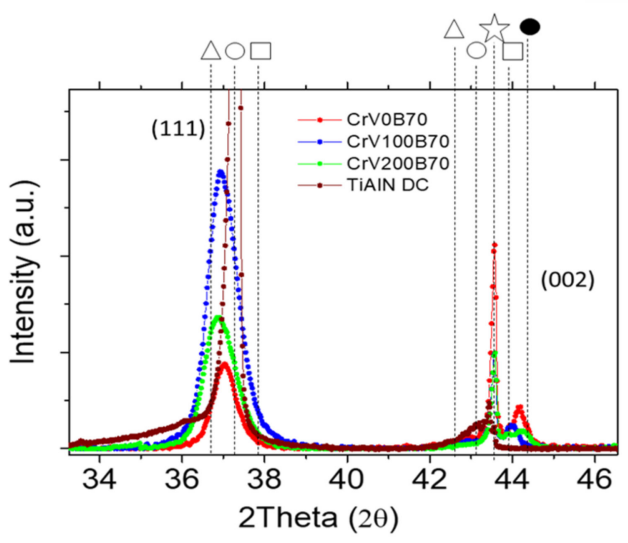

(a)

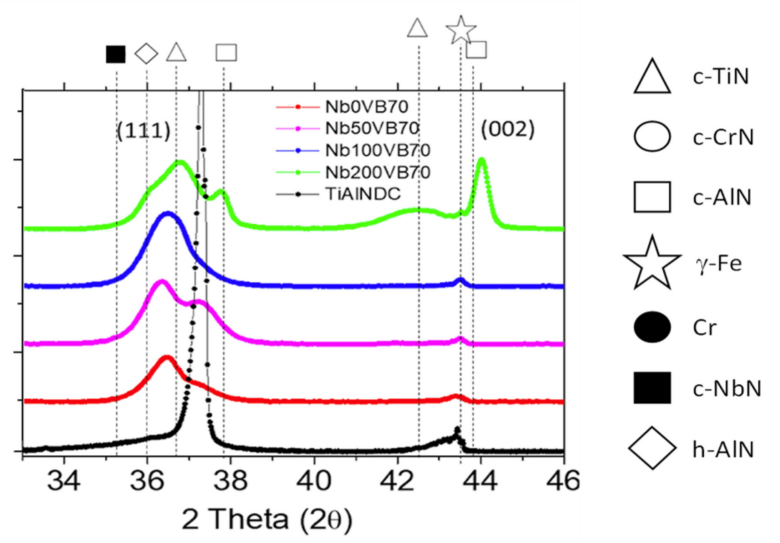

(b)

Figure 6. XRD spectra from $(\mathrm{TiAl})_{1-\mathrm{x}}(\mathrm{Cr})_{\mathrm{X}} \mathrm{N}(\mathbf{a})$ and $(\mathrm{TiAl})_{1-\mathrm{x}}(\mathrm{Nb})_{\mathrm{X}} \mathrm{N}(\mathbf{b})$ fillms applying different positive pulses on $\mathrm{Cr}, \mathrm{Nb}$ targets during deposition. XRD spectrum from TiAlN DCMS film depicted for reference.

TiAlN films are often composed by a single face-centered cubic phase, corresponding to the $\delta$ - $\mathrm{Ti}(\mathrm{Al}) \mathrm{N}$ rock-salt B1 crystal structure [13], as shown in the TiAlN DC pattern by the appearance of the peaks situated at $2 \theta \approx 37.3^{\circ}$ and $2 \theta \approx 43.5^{\circ}$. These peaks correlate to the (111) and (200) found in the face-centered cubic crystalline systems. The intensity of the (111) peak is very high, denoting a predominant (111) growth orientation over the (200), and a high degree of crystallinity with large grains present in the coating with similar composition. The (200) peak, however, is broader and lower in intensity than the (111), which might be the resultant from much lower size crystals showing this orientation.

In the case of the $(\mathrm{TiAl})_{1-\mathrm{x}}(\mathrm{Cr})_{\mathrm{X}} \mathrm{N}$ XRD spectra (Figure 6a), three peaks are shown at $2 \theta \approx 37.3^{\circ}, 2 \theta \approx 43^{\circ}$ and $2 \theta \approx 44^{\circ}$. The peaks appearing at $2 \theta \approx 37.3^{\circ}$ and $2 \theta \approx 43^{\circ}$ are correlated with the (111) and (200) diffraction planes from a single-phase face-centered cubic structure. In this phase, the $\mathrm{Cr}$ atoms could insert in the TiAlN matrix replacing 
either the Ti or the $\mathrm{Al}$ atoms. The (111) peak, although still being the highest in intensity, is broader and much lower in intensity when compared to the original TiAlN DCMS XRD pattern, pointing out that these coatings are overall less crystalline and are composed of smaller grains with an array of different $\mathrm{Ti}_{\mathrm{x}} \mathrm{Al}_{\mathrm{y}} \mathrm{Cr}_{\mathrm{z}} \mathrm{N}$ compositions. When comparing the shape of the peaks as a function of the positive pulse voltage, it can be seen that the (111) peak changes in intensity; from the lowest at $0 \mathrm{~V}$; to the highest at $100 \mathrm{~V}$, to then drop down again at $200 \mathrm{~V}$. This phenomenon could indicate that the energy of the incident metallic atoms at $100 \mathrm{~V}$ is enough to compress and densify the film via the low-energy recoil, maintaining the cubic (111) orientation with bigger crystal grains. On the other hand, the higher energy of the incident atoms at $200 \mathrm{~V}$ is superior and could promote the destruction of the cubic lattice, resulting in smaller crystal grains and the amorphization of the film. It must be noted that the (111) peaks also shift to lower diffraction angles as the voltage of the positive pulses is increased, which could be the result of the higher-energy incident atoms inducing higher compressive stress to the coatings, as can be observed in Figure $5 \mathrm{~b}$. The peak that appears at $2 \theta \approx 44^{\circ}$ can be correlated with the (200) peak from the pure $\mathrm{Cr}$ bonding layer that was deposited to enhance the adhesion in this series. As explained in the experimental section, the positive pulse was also applied during bonding layer deposition to ensure process stabilization during the nitrogen addition, which might explain the shift of the diffraction peak to lower angles as positive pulse increases. It is also worth mentioning the decrease of the $\mathrm{Cr}$ bonding diffraction peak intensity with higher positive pulse voltage amplitudes which follows the same trend with the $\gamma$-Fe substrate peak at $2 \theta \approx 43.5^{\circ}$ which might be related with the increase of $(\mathrm{TiAl})_{1-\mathrm{x}}(\mathrm{Cr})_{\mathrm{X}} \mathrm{N}$ density.

In the case of the (TiAl) ${ }_{1-x}(\mathrm{Nb})_{\mathrm{X}} \mathrm{N}$ XRD spectra (Figure $6 \mathrm{~b}$ ), two peaks can be observed at lower positive pulse voltages at $2 \theta \approx 36.5^{\circ}$ and $2 \theta \approx 37.4^{\circ}$. However, at $200 \mathrm{~V}$ positive pulse voltage, five peaks appear at $2 \theta \approx 36^{\circ}, 2 \theta \approx 36.5^{\circ}, 2 \theta \approx 37.8^{\circ}, 2 \theta \approx 42.5^{\circ}$ and $2 \theta \approx 44.3^{\circ}$. The peaks showing at $2 \theta \approx 36.5^{\circ}$ and $2 \theta \approx 42.5^{\circ}$ are again correlated to the (111) and (200) peaks present in face-centered cubic lattices but are heavily displaced to lower diffraction angles which could be a result of the combined effect from the higher compressive stress developed in the coatings after ion bombardment and $\mathrm{Nb}$ being inserted in the TiAlN matrix. The peak that appears at $2 \theta \approx 37.4^{\circ}$ at lower positive pulse voltages can be assigned to the (110) peak from $c-\mathrm{Nb}$, present in the $\mathrm{Nb}$ bonding layer deposited in this series. At $200 \mathrm{~V}$ positive pulse, as the energy from the incident atoms is very high, the metastable cubic lattice suffers a spinodal decomposition resulting in cubic Ti-rich and Al-rich phases, which can be denoted by the peaks appearing at $2 \theta \approx 36.5^{\circ}$ and $42.5^{\circ}$ (cubic Ti-rich phase) and $2 \theta \approx 37.8^{\circ}$ and $44.3^{\circ}$ (cubic Al-rich phase). The decomposition of the metastable cubic lattice implies a drop in mechanical properties and the appearance of a hexagonal wurtzite-type $\mathrm{B} 4 \mathrm{AlN}$ phase at $2 \theta \approx 36^{\circ}$ [14] further decreases its performance. Overall, the peaks on the $(\mathrm{TiAl})_{1-\mathrm{x}}(\mathrm{Nb})_{\mathrm{X}} \mathrm{N}$ XRD patterns are broad and of low intensity, again showing the low crystallinity and inhomogeneous composition nature of these films.

\section{Conclusions}

The concept of selective metal ion bombardment using bipolar HIPIMS has been introduced and experimentally demonstrated. The process consists of the combination of conventional DCMS deposition of a transition metal nitride matrix (TiAlN in this particular case) with the subsequent irradiation with metal ions a different kinetic energy. Two distinct metal ions having a large difference in atomic mass were selected: $\mathrm{Nb}$ and $\mathrm{Cr}$. The positive acceleration voltage was varied from 0 to $+200 \mathrm{~V}$. The resulting film mechanical and microstructural properties were correlated with the plasma parameters, mainly, with the metal ion acceleration voltage.

In all the cases, films showed densification as the acceleration voltage increases while maintaining a low atomic composition content of the irradiating metal in the resulting film $(<10$ at $\%)$. Under these conditions, the results for the light metal ion are more promising. The $\mathrm{Cr}$ bombardment allows a hardness improvement from 7 to $22 \mathrm{GPa}$ as well as a reduced film accumulated stress at the highest positive acceleration voltage. From the 
XRD measurements it is observed that the $\mathrm{Cr}$ atoms are inserted into the TiAlN cubic matrix maintaining its crystalline structure. However, the bombardment with the highmass metal ion $(\mathrm{Nb})$ promotes the deformation of the cubic TiAlN matrix, resulting in a spinodal decomposition and further degradation of the crystalline structure with the appearance of the hexagonal wurtzite-type Al-rich phase. This is also translated to the resulting film mechanical properties, as hardness rapidly decrease from 25 to $10 \mathrm{GPa}$ and stress raises linearly with the positive voltage acceleration. This does not mean that under other deposition conditions the use of heavier metal ions cannot produce transition metal nitride coatings with improved mechanical properties, for example, using much lower metal ion energies or doses.

The paper aims to demonstrate a novel PVD deposition method which is very relevant to the hard coating industrial community. The selective metal ion acceleration method allows the deposition of films with optimum mechanical properties as well as reduced accumulated stress compared to films deposited with gas-ion bombardment typical for direct current magnetron sputtering (DCMS) in a standard industrial batch coater. Applications ranging from low temperature deposition of dense hard coatings (low energy bombardment with heavy metal ions) or low stress- high $\mathrm{Al}$ content ( $\mathrm{Ti}, \mathrm{Cr}) \mathrm{AlN}$ metastable cubic phases (high energy bombardment and implantation with Al light metal ions) are envisaged for this method.

Author Contributions: Conceptualization, I.F.-M., J.A.S., M.A.M. and J.M.-A.; methodology, I.F.-M., J.A.S., M.A.M. and J.M.-A.; validation, I.F.-M., J.A.S. and M.A.M.; formal analysis, I.F.-M., J.A.S., M.A.M. and J.M.-A.; investigation, I.F.-M., J.A.S., Á.M., M.P.-L., P.D.-R., L.M., J.D.-S.; C.Z.; M.A.M. and J.M.-A.; resources, I.F.-M. and J.M.-A.; data curation, I. F.-M., J.A.S., Á.M., M.P.-L., P.D.-R., L.M., J.D.-S., C.Z. and J.M.-A.; writing—original draft preparation, I.F.-M., J.A.S., Á.M., M.P.-L., P.D.-R., L.M.; J.D.-S.; C.Z.; M.A.M. and J.M.-A.; writing-review and editing, I.F.-M., J.A.S., P.D.-R. and J.M.-A.; visualization, I.F.-M. and J.M.-A.; supervision, I.F.-M. and J.M.-A.; project administration, I.F.-M., L.M., J.D.-S. and J.M.-A.; funding acquisition, I.F.-M., L.M., J.D.-S. and J.M.-A. All authors have read and agreed to the published version of the manuscript.

Funding: This research was funded by three different organizations and programs: 1 . CDTi - Spain under the Cervera programme. Grant number: ref. 00122572/CER-20191003.; 2. Comunidad de Madrid under the Industrial Doctorate program (IND2018/IND-9668); 3. Eurostars-2 program. Grant number: E!114350. Project Acronym: Hip-3D.

Institutional Review Board Statement: Not applicable.

Informed Consent Statement: Not applicable.

Data Availability Statement: Not applicable.

Conflicts of Interest: The authors declare no conflict of interest.

\section{References}

1. Greczynski, G.; Mráz, S.; Schneider, J.M.; Hultman, L. Metal-ion subplantation: A game changer for controlling nanostructure and phase formation during film growth by physical vapor deposition. J. Appl. Phys. 2020, 127, 180901. [CrossRef]

2. Li, X.; Bakhit, B.; Jöesaar, M.J.; Hultman, L.; Petrov, I.; Greczynski, G. Toward energy-efficient physical vapor deposition: Routes for replacing substrate heating during magnetron sputter deposition by employing metal ion irradiation. Surf. Coat. Technol. 2021, 415, 127120. [CrossRef]

3. Eichenhofer, G.; Fernandez-Martinez, I.; Wennberg, A. Industrial use of HiPIMS and the hiP-V hiPlus technology. VIP 2017, 29, 40-44. [CrossRef]

4. Britun, N.; Michiels, M.; Godfroid, T.; Snyders, R. Ion density evolution in a high power sputtering discharge with bipolar pulsing. Appl. Phys. Lett. 2018, 112, 234103. [CrossRef]

5. Macák, K.; Kouznetsov, V.; Schneider, J.; Helmersson, U. Ionized sputter deposition using an extremely high plasma density pulsed magnetron discharge. J. Vac. Sci. Technol. A 2000, 18, 1533. [CrossRef]

6. Wu, B.; Haehnlein, I.; Shchelkanov, I.; McLain, J.; Patel, D.; Uhlig, J.; Jurczyk, B.; Leng, Y.; Ruzic, D.N. Cu films prepared by bipolar pulsed high power impulse magnetron sputtering. Vacuum 2018, 150, 216-221. [CrossRef]

7. Keraudy, J.; Viloan, R.P.B.; Raadu, M.; Brenning, N.; Lundin, D.; Helmersson, U. Bipolar HiPIMS for tailoring ion energies in thin film deposition. Surf. Coat. Technol. 2019, 359, 433-437. [CrossRef] 
8. Avino, F.; Sublet, A.; Taborelli, M. Evidence of ion energy distribution shift in HiPIMS plasmas with positive pulse. Plasma Sources Sci. Technol. 2019, 28, 01LT03. [CrossRef]

9. Viloan, R.P.B.; Helmersson, U.; Lundin, D. Copper thin films deposited using different ion acceleration strategies in HiPIMS. Surf. Coat. Technol. 2021, 422, 127487. [CrossRef]

10. Münz, W. Titanium aluminum nitride films: A new alternative to TiN coatings. J. Vac. Sci. Technol. A 1986, 4, 2717-2725. [CrossRef]

11. Viloan, R.P.B.; Zanáška, M.; Lundin, D.; Helmersson, U. Pulse length selection for optimizing the accelerated ion flux fraction of a bipolar HiPIMS discharge. Plasma Sources Sci. Technol. 2020, 29, 125013. [CrossRef]

12. Mendez, A.; Monclus, M.A.; Santiago, J.A.; Fernandez-Martinez, I.; Rojas, T.C.; Garcia-Molleja, J.; Avella, M.; Dams, N.; PanizoLaiz, M.; Molina-Aldareguia, J.M. Effect of Al content on the hardness and thermal stability study of AlTiN and AlTiBN coatings deposited by HiPIMS. Surf. Coat. Technol. 2021, 422, 127513. [CrossRef]

13. JCPDS-ICDD 00-038-1420 for Cubic Titanium Nitride Pattern. Available online: https://www.icdd.com/pdfsearch/ (accessed on 30 December 2021)

14. JCPDS-ICDD 00-025-1133 for Hexagonal Aluminum Nitride Pattern. Available online: https://www.icdd.com/pdfsearch/ (accessed on 30 December 2021) 